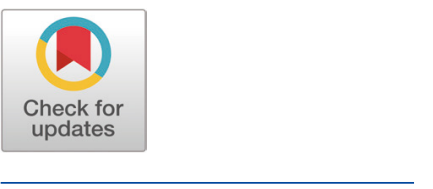

Received: Nov 20, 2019

Revised: Dec 16, 2019

Accepted: Dec 28, 2019

*Corresponding author Jin $\mathrm{Ho}$ Cho

Division of Food and Animal Science, Chungbuk National University,

Cheongju 28644, Korea.

Tel: +82-43-261-2544

E-mail: jinhcho@chungbuk.ac.kr

Copyright (๑ 2020 Korean Society of Animal Sciences and Technology. This is an Open Access article distributed under the terms of the Creative Commons Attribution Non-Commercial License (http:// creativecommons.org/licenses/by$\mathrm{nc} / 4.0 /$ ) which permits unrestricted non-commercial use, distribution, and reproduction in any medium, provided the original work is properly cited.

ORCID

Ji Seon An

https://orcid.org/0000-0002-9205-8095 Won Yun

https://orcid.org/0000-0002-1835-2640 Ji Hwan Lee

https://orcid.org/0000-0001-8161-4853 Han Jin Oh

https://orcid.org/0000-0002-3396-483X Tae Heon Kim

https://orcid.org/0000-0001-9054-5781

Eun Ah Cho

https://orcid.org/0000-0002-3445-1905 Gok Mi Kim

https://orcid.org/0000-0003-1053-4535 Ki Hyun Kim

https://orcid.org/0000-0002-9834-2126

\section{Effects of exogenous emulsifier supplementation on growth performance, energy digestibility, and meat quality in broilers}

\author{
Ji Seon $\mathrm{An}^{1}$, Won Yun ${ }^{1}$, Ji Hwan Lee ${ }^{1}$, Han Jin Oh${ }^{1}$, Tae Heon Kim", \\ Eun Ah $\mathrm{Cho}^{1}$, Gok Mi Kim², Ki Hyun Kim³ ${ }^{3}$ Sung Dae Lee ${ }^{4}$ and Jin Ho Cho ${ }^{1 *}$ \\ ${ }^{1}$ Division of Food and Animal Science, Chungbuk National University, Cheongju 28644, Korea \\ ${ }^{2}$ Department of Beauty Art, Yonam College, Cheonan 31005, Korea \\ ${ }^{3}$ Animal Welfare Research Team, National Institute of Animal Science, Rural Development \\ Administration, Cheonan 31000, Korea \\ ${ }^{4}$ Animal Nutrition and Physiology Team, National Institute of Animal Science, Rural Development \\ Administration, Cheonan 31000, Korea
}

\section{Abstract}

This experiment was conducted to investigate the effects of exogenous emulsifier supplementation on growth performance, energy digestibility, and meat quality in broilers. A total of 60 Ross 308 broilers were treated for two weeks. The three dietary treatments were: (CON) basal diet; (T1) basal diet $+0.1 \%$ exogenous emulsifier, and (T2) basal diet $+0.2 \%$ exogenous emulsifier. In Period 1 ( $0-7$ days), broilers in the T2 group showed significantly higher body weight gain (BWG) $(p<0.05)$ and broilers in the T1 and T2 treatment groups had significantly lower feed conversion ratios (FCR) $(p<0.05)$. In Period 2 (8-14 days), broilers in the T2 treatment group had significantly higher feed intake $(\mathrm{FI})(p<0.05)$. Therefore, in this experiment (from days 0 to 19), BWG and FCR were affected $(p<0.05)$ by the T1 and T2 treatments. Additionally, the T1 and T2 treatments with added exogenous emulsifier in the broiler feed showed significantly higher energy digestibility $(p<0.05)$ than the CON treatment. Broilers fed the T2 diet had higher water-holding capacity (WHC) $(p<0.05)$ and cooking loss than the broilers fed the CON and T1 diets. Moreover, the shearing force in the meat was decreased $(p<0.05)$ in broilers fed the T2 diet. In conclusion, supplementation with exogenous emulsifier to broiler diets improved growth performance, energy digestibility, and meat quality. The optimal amount of exogenous emulsifier supplementation requires further investigation.

Keywords: Broiler, Energy digestibility, Exogenous emulsifier, Growth performance, Meat quality

\section{INTRODUCTION}

An emulsifier can disperse liquids by reducing the surface tension between two substances that are difficult to mix and increase the penetration depth [1,2]. Because of these characteristics, emulsifiers are commonly used as additives to foods, such as bread and ice cream [3]. 
Sung Dae Lee

https://orcid.org/0000-0002-9167-4099

Jin Ho Cho

https://orcid.org/0000-0001-7151-0778

Competing interests

The authors declare no conflict of interest.

Funding sources

This experiment was conducted with the support of Samgyetang Export Research

Group (Project No. 617074-05-2-HD230)

of the Korea Institute of Planning and

Evaluation for Technology in Food,

Agriculture and Forestry (IPET).

Acknowledgements

Not applicable.

Availability of data and material

Upon reasonable request, the datasets

of this study can be available from the

corresponding author.

Authors' contributions

Conceptualization: An JS, Cho JH.

Data curation: An JS.

Formal analysis: An JS, Kim KH, Lee SD.

Investigation: Yun W, Lee JH, Oh HJ, Kim TH,

Cho EA, Kim GM.

Writing - original draft: An JS.

Writing - review \& editing: Cho JH.

Ethics approval and consent to participate The experimental protocol was approved and conducted under the guidelines of the Animal Care and Use Committee of Chungbuk National University.
Emulsifiers play a diverse role in the livestock industry. As a feed additive, it aids the digestion and absorption of added fat in feed to increase the productivity of broilers and weaning pigs [4]. The supplementation of emulsifiers in feed with vegetable fat was reported to increase growth performance significantly and improve fatty acid digestibility in broilers $[5,6]$. The digestibility of major nutrients, such as protein and energy, as well as fat, is also increased to improve growth performance [7]. The addition of emulsifiers to feed reduces the viscosity of the digesta, increasing the amount of transfer to the digestive tract [8]. Supplementation with emulsifiers has been shown to effectively reduce the size of the fat globules in feed, thereby increasing the total available surface area for the digestive enzymes [9-14].

The addition of emulsifiers to the feed production process improves the quality of the pellets by controlling the moisture content of the pellets to increase humidity and reduce energy consumption [15]. For this reason, studies of emulsifying agents in livestock have focused on using lecithin to improve the growth performance and digestibility in monogastric animals [11,16]. Therefore, this study was conducted to investigate the effects of supplementation with exogenous emulsifier on the growth performance, energy digestibility, and the meat quality of broilers.

\section{MATERIALS AND METHODS}

The experimental protocol was approved and conducted under the guidelines of the Animal Care and Use Committee of Chungbuk National University.

\section{Experimental design and animals}

A total of sixty 10 -day-olds ( $184.4 \pm 2.3 \mathrm{~g})$ ROSS 308 broilers were used in 19 days. All birds randomly allocated into 3 groups, with 10 replicates per group and 2 chickens per cage that was made with stainless steel of identical size $(50 \times 35 \times 35 \mathrm{~cm})$. The experiment period was of 19 days. The dietary treatments were as follows: (1) control, basal diet (CON), (2) basal diet $+0.1 \%$ exogenous emulsifier (T1), (3) basal diet + 0.2\% exogenous emulsifier (T2). Exogenous emulsifier (Lipidol ${ }^{\circledR}$, Easybio Co., Korea) used in this experiment contains lysolecithin. The basal diets were formulated to meet or exceed the NRC [17] requirements (Table 1). All broilers were allowed to consume feed and water ad libitum.

\section{Sampling and measurements}

The broilers were weighed individually, and body weight was recorded initially and end of the experimental period (19-days) to calculate body weight gain (BWG), feed intake (FI), and feed conversion ratio (FCR). Chromium oxide at $0.2 \%$ was supplemented to the diets on the 7 days before the end of the experimental period, as a marker for the apparent digestibility of gross energy. Fresh fecal and feed samples were gathered from each cage at the end of the experiment. Fecal samples were dried at $70^{\circ} \mathrm{C}$ for 72 hours in a forced air oven and ground and screened with a 1-mm screen. The gross energy of diets and feces was analyzed using an adiabatic oxygen bomb calorimeter (Parr Instruments, Moline, IL, USA).

The 10 broilers were randomly selected from each treatment. The selected broilers were sacrificed by cervical dislocation and exsanguinated. And the breast meat was removed and weighed. The breast muscle was analyzed immediately. Its Hunter lightness $\left(L^{*}\right)$, redness $\left(a^{*}\right)$ and yellowness $\left(b^{*}\right)$ values were determined by Spectro color meter (Color Techno System Co Ltd, Tokyo, Japan). The $\mathrm{pH}$ values values of each sample were measured using a $\mathrm{pH}$-meter (WTW, Weilheim, Germany). The water-holding capacity (WHC) was measured with the methods described by Laakkonenen et al. [18]. The shearing force was determined using a Shearing, Cutting Test by Rheo meter (Sun Sci- 


\begin{tabular}{|c|c|}
\hline Items & Content \\
\hline \multicolumn{2}{|l|}{ Ingredients (\%) } \\
\hline Corn & 50.28 \\
\hline Soybean meal $(44 \% \mathrm{CP})$ & 16.50 \\
\hline Wheat & 20.00 \\
\hline Wheat bran & 4.00 \\
\hline Fish meal & 1.00 \\
\hline Animal fat & 3.00 \\
\hline Rapeseed meal & 2.00 \\
\hline Salt & 0.23 \\
\hline Choline- $\mathrm{HCl}(50 \%)$ & 0.01 \\
\hline DL-Methionine-99\% & 0.12 \\
\hline Lysine-HCl $(78 \%)$ & 0.66 \\
\hline Calcium carbonate & 0.20 \\
\hline Tricalcium phosphate & 1.60 \\
\hline Vitamin premix ${ }^{1)}$ & 0.20 \\
\hline Mineral premix ${ }^{2)}$ & 0.20 \\
\hline \multicolumn{2}{|l|}{ Analyzed composition (\%) } \\
\hline Crude protein & 22 \\
\hline $\mathrm{Ca}$ & 1 \\
\hline Lysine & 1.2 \\
\hline Met + Cys & 0.87 \\
\hline
\end{tabular}

${ }^{1)}$ Contained per kg of diet: vitamin A, 10,000 IU; vitamin $\mathrm{D}_{3}, 2,000 \mathrm{IU}$; vitamin $\mathrm{E}, 421 \mathrm{IU}$; vitamin $\mathrm{K}, 5 \mathrm{mg}$; riboflavin, 2,400 mg; vitamin $\mathrm{B}_{2}, 9.6 \mathrm{mg}$; vitamin $\mathrm{B}_{6}, 2.45 \mathrm{mg}$; vitamin $\mathrm{B}_{12}, 40 \mathrm{ug}$; niacin, $49 \mathrm{mg}$; pantothenic acid, $27 \mathrm{mg}$, biotin, $0.05 \mathrm{mg}$.

${ }^{2)}$ Contained the mg per kg of diet: Cu 140 mg, Fe 145 mg, Zn 179 mg, Mn 12.5 mg, I 0.5 mg, Co 0.25 mg, Se 0.4 mg.

entific Co Ltd, Tokyo, Japan). Breast samples were heated in a water bath at $70^{\circ} \mathrm{C}$ and then chilled to room temperature for 30 minutes. The samples $[1.0 \mathrm{~cm}$ (width) $\times 2.0 \mathrm{~cm}$ (thickness) $\times 1.0 \mathrm{~cm}$ (length)] were measured max weight. The shearing force test condition was as follows: table speed of $110 \mathrm{~mm} / \mathrm{min}$, Graph interval of $20 \mathrm{msec}$ and Load cell (max) of $10 \mathrm{~kg}$ using the RDS (Rheology Data System, Tokyo, Japan) Ver 2.01. For cooking loss determination, each breast was weighed and sealed in a polypropylene bag and cooked by immersion in a $70^{\circ} \mathrm{C}$ water bath for 40 minutes. After cooking, the samples were chilled by immersion of the bags in an ice water bath for 30 minutes. Each piece of the breast was then weighed and calculated. For drip loss determination, breast samples were kept suspended in a sealed polypropylene bag at $4{ }^{\circ} \mathrm{C}$ for $24 \mathrm{~h}$, and loss was calculated as the percentage of weight loss during storage. The TBARS was measured with the extraction method of Witte et al. [19] and was marked as mg malonaldehyde per 1,000 $\mathrm{g}$ of samples.

\section{Statistical analysis}

Data were statistically analyzed by ANOVA using the GLM procedure SAS ver 9.4 (SAS Institute Inc., Cary, USA), with each cage being used as the experimental unit. Differences among all treatment means were determined using the Duncan's multiple range tests with a $p<0.05$ indicating a significance. 


\section{RESULTS AND DISCUSSION}

\section{Growth performance}

Table 2 presents the effect of exogenous emulsifier supplementation of broiler feed on growth performance. At the end of the experiment, the final body weight of the broilers was significantly higher $(p<0.05)$ in broilers fed the T2 diet than in the other treatment groups. In Period 1 , broilers in the T2 treatment group showed significantly higher body weight gain (BWG) $(p<0.05)$ compared to the other treatments and broilers in the T1 and T2 treatment groups had significantly lower feed conversion ratios (FCR) $(p<0.05)$ than broilers in the CON treatment group. In Period 2, broilers in the T1 treatment group had significantly higher BWG $(p<0.05)$ than broilers in other treatment groups and broilers in the T2 treatment group had significantly higher feed intake $(\mathrm{FI})(p$ $<0.05)$. The FCR was decreased $(p<0.05)$ in the T1 treatment group. From day 15 to 19 (Period 3), there was no significant difference $(p>0.05)$ on growth performance among the dietary treatment groups. During the overall period, broilers in the T1 and T2 treatment groups showed increased BWG $(p<0.05)$. The FCR was significantly lower $(p<0.05)$ in the T1 treatment group than in the other treatment groups.

In a study conducted on broilers, the results of supplementation lysolecithin in feed showed no significant effect on the growth performance of the broilers for one to 21 days [20]. In a similar study, Dabbou et al. [21] reported that supplementation with natural emulsifiers for one to 10 days significantly decreased the FCR in broilers, but there were no significant differences in BWG or FI. In contrast, a study by Bontempo et al. [15] showed a significant improvement in average daily gain with the supplementation of synthetic emulsifier to the feed for one to 12 days and a significant decline in the FCR for 22 to 44 days. The results of this study also showed a significant difference

Table 2. Effect of supplemental exogenous emulsifier on growth performance in broilers

\begin{tabular}{|c|c|c|c|c|c|}
\hline Item & CON & T1 & T2 & SE & $p$-value \\
\hline Initial BW (10 d Broiler) & 181.7 & 185.0 & 186.7 & 2.7 & 0.412 \\
\hline Final BW (29 d Broiler) & $1,337.9^{c}$ & $1,382.7^{b}$ & $1,406.0^{a}$ & 5.0 & 0.005 \\
\hline \multicolumn{6}{|l|}{ Period 1 (d 0 to 7 ) } \\
\hline Weight gain (g) & $348.3^{b}$ & $341.7^{b}$ & $374.2^{\mathrm{a}}$ & 3.4 & 0.013 \\
\hline Feed intake (g) & 496.7 & 460.8 & 500.0 & 12.9 & 0.203 \\
\hline Feed conversion ratio $(\mathrm{g} / \mathrm{g})$ & $1.426^{b}$ & $1.349^{\mathrm{a}}$ & $1.336^{\mathrm{a}}$ & 0.032 & 0.025 \\
\hline \multicolumn{6}{|l|}{ Period 2 (d 8 to 14 ) } \\
\hline Weight gain (g) & $460.8^{b}$ & $490.0^{\mathrm{a}}$ & $471.7^{b}$ & 17.6 & 0.047 \\
\hline Feed intake $(\mathrm{g})$ & $718.3^{b}$ & $715.8^{b}$ & $755.0^{\mathrm{a}}$ & 14.1 & 0.042 \\
\hline Feed conversion ratio $(\mathrm{g} / \mathrm{g})$ & $1.559^{b}$ & $1.461^{\mathrm{a}}$ & $1.601^{b}$ & 0.063 & 0.038 \\
\hline \multicolumn{6}{|l|}{ Period 3 (d 15 to 19 ) } \\
\hline Weight gain (g) & 347.0 & 366.0 & 373.5 & 32.4 & 0.845 \\
\hline Feed intake (g) & 523.3 & 534.7 & 551.3 & 21.2 & 0.926 \\
\hline Feed conversion ratio $(\mathrm{g} / \mathrm{g})$ & 1.508 & 1.461 & 1.476 & 0.014 & 0.178 \\
\hline \multicolumn{6}{|l|}{ Overall period (d 0 to 19$)$} \\
\hline Weight gain $(\mathrm{g})$ & $1,156.2^{b}$ & $1,197.7^{\mathrm{a}}$ & $1,219.3^{a}$ & 6.7 & 0.016 \\
\hline Feed intake (g) & $1,738.3$ & $1,711.3$ & $1,806.3$ & 24.0 & 0.136 \\
\hline Feed conversion ratio $(\mathrm{g} / \mathrm{g})$ & $1.503^{\mathrm{a}}$ & $1.429^{b}$ & $1.481^{\mathrm{ab}}$ & 0.014 & 0.064 \\
\hline
\end{tabular}


in the FCR and BWG in the group treated with added exogenous emulsifier in Period 1 and there were significant effects on BWG, FI, and FCR in Period 2 in the group treated with feed containing exogenous emulsifier. Improvement in the growth performance of the broilers may be the result of increased fatty acid and nutrient digestibility [6]. However, the feed intake of broilers may vary depending on the size of the feed, which requires a more precise study of growth performance.

\section{Energy digestibility}

The effect of supplementation with exogenous emulsifier in feed on energy digestibility is shown in Table 3. Broilers fed T1 and T2 diets had significantly higher energy digestibility $(p<0.05)$ compared to broilers fed CON diet.

A study by Zhao and Kim [22] showed that the supplementation of emulsifiers to broiler feed significantly improved energy digestibility. Experiments with globin in broiler feed resulted in improved energy digestibility and increased energy efficiency [21]. Also, supplementation with glyceryl polyethylene glycol ricinoleate in the broiler feed increased the ATTD of GE to improve growth performance [23]. The supplementation of emulsifiers to low-energy feeds, as well as general feeds, has been shown to improve energy digestibility [21]. Similar to the previous study, the results of this experiment also showed that the energy digestibility of broilers was improved when exogenous emulsifier was added to the feed.

Energy digestibility with the addition of emulsifiers may vary depending on the composition and proportion of the fat source in the feed [6,24,25]. Jansen et al. [26] reported that the supplementation of emulsifiers to a fat source with low digestibility significantly affected nutrient digestibility. This study suggested that the addition of exogenous emulsifier was effective in improving energy digestibility depending on the fat source in the normal diet.

\section{Meat quality characteristics}

The effect of supplemental exogenous emulsifier on meat quality characteristics of chicken breast is presented Table 4. At the end of the experiment, there was no significant difference in the water content and the drip loss among broilers in the treatment groups $(p>0.05)$. The WHC was significantly higher in the T2 treatment group compared to the CON group $(p<0.05)$. Shearing force was significantly reduced $(p<0.05)$ in the T2 treatment group compared to the CON group, resulting in soft meat. In contrast, the cooking loss was significantly higher $(p<0.05)$ in the T1 and $\mathrm{T} 2$ treatment group than in the $\mathrm{CON}$ group.

The WHC of meat refers to the property of retaining moisture in the meat when an external physical force, such as cutting and heat treatment, is applied [27]. The WHC affects a variety of properties, such as texture and meat color, and increases with changes in the protein structure and ionic level [28]. The experimental results of low-energy feed in broiler showed that the WHC was significantly decreased when emulsifiers were added [29]. The study by Upadhaya et al. [30] also found that the supplementation of emulsifiers reduced the WHC of broiler meat. However, the present study showed the opposite result, which may have been due to the difference in energy levels in the feed and the type of emulsifiers.

Table 3. Effect of supplemental exogenous emulsifier on energy digestibility in broilers

\begin{tabular}{lccccc}
\hline Item & CON & T1 & T2 & SE & $p$-value \\
\hline Gross energy & $72.74^{\mathrm{b}}$ & $77.15^{\mathrm{a}}$ & $76.53^{\mathrm{a}}$ & 1.50 & 0.021 \\
\hline Each value is the mean value of 10 replicates $(2$ broilers/cage). & & & \\
a,b Means in the same row with different superscripts differ $(p<0.05)$. \\
CON, basal diet; $\mathrm{T} 1$, basal diet $+0.1 \%$ exogenous emulsifier; $\mathrm{T} 2$, basal diet $+0.2 \%$ exogenous emulsifier; SE, standard error.
\end{tabular}


Drip loss is exudate caused by the formation of gaps in muscle fibers over time after slaughter and tends to decrease as the pH decreases [31-33]. Kim et al. [34] and Akit et al. [35] did not find a significant difference in the drip loss of broiler meat when lecithin was added to the broiler feed. In addition, an experiment with glyceryl-type emulsifiers in broiler feed showed no significant difference in drip loss [29]. Similarly, the results of the current study also showed no significant difference in drip loss, which suggests that the emulsifier does not affect the drip loss of meat.

Regardless of the heating method, when meat is heated, the WHC of the meat is reduced due to the contraction and shortening of the muscle fibers, resulting in a water loss [36]. Also, the shearing force of meat decreases as the storage period increases. This is because the protein is decomposed by the enzymes of microorganisms, as well as intramuscular enzymes, softening tissues and increasing non-protein nitrogen compounds [37]. Shearing force is more explicitly related to muscle fibers than to the collagen content of cooked meat [38]. The addition of lecithin, to pig feed reduced pork elasticity and hardness, but did not significantly change the shearing force values and reduce the cooking loss [35,39]. This is because lecithin affects collagen more than muscle fibers. The addition of exogenous emulsifier in this study affected muscle fibers, regardless of collagen, resulting in decreased shearing force and increased cooking loss.

\section{Meat storage characteristics}

Table 5 presents the effect of exogenous emulsifier in broiler feed on meat storage characteristics. The $\mathrm{pH}$ was not meaningfully different between the treatments $(p>0.05)$. In the TBARS assay, which measures the rancidity of fat, the results were lower in the T1 and T2 treatment groups than in the CON treatment and were significantly lowest in the T2 group $(p<0.05)$.

The $\mathrm{pH}$ value is closely related to meat quality characteristics, such as the $\mathrm{WHC}$ and shearing force [40]. When lecithin was added to pig feed, the $\mathrm{pH}$ of pork was not significantly changed [35]. Also, the $\mathrm{pH}$ of broiler meat did not show a significant difference in experiments with the addition of emulsifiers to low-density feed [41]. The results of the previous studies were similar to this experiment. In general, after slaughter, the $\mathrm{pH}$ of the muscle drops from $\mathrm{pH} 7.0$ to $\mathrm{pH}$ 5.4-6.0 within 24

Table 4. Effect of supplemental exogenous emulsifier on meat quality characteristics of chicken breast from broilers

\begin{tabular}{lccccc}
\hline \multicolumn{1}{c}{ Item } & CON & T1 & T2 & SE & p-value \\
\hline Water content (\%) & 73.83 & 73.18 & 73.65 & 0.22 & 0.492 \\
Water holding capacity (\%) & $55.01^{\mathrm{b}}$ & $56.37^{\mathrm{ab}}$ & $58.27^{\mathrm{a}}$ & 0.95 & 0.044 \\
Drip loss (\%) & 3.79 & 3.62 & 3.82 & 0.08 & 0.357 \\
Cooking loss (\%) & $15.92^{\mathrm{c}}$ & $19.36^{\mathrm{b}}$ & $20.42^{\mathrm{a}}$ & 0.21 & 0.001 \\
Shearing force (g) & $2,383.5^{\mathrm{a}}$ & $2,267.9^{\mathrm{ab}}$ & $2,101.2^{\mathrm{b}}$ & 53.4 & 0.024 \\
\hline
\end{tabular}

Each value is the mean value of 10 replicates ( 2 broilers/cage).

${ }^{a-c}$ Means in the same row with different superscripts differ $(p<0.05)$.

CON, basal diet; $\mathrm{T} 1$, basal diet $+0.1 \%$ exogenous emulsifier; $\mathrm{T} 2$, basal diet $+0.2 \%$ exogenous emulsifier; SE, standard error.

Table 5. Effect of supplemental exogenous emulsifier on storage characteristics of chicken breast from broilers

\begin{tabular}{lccccc}
\hline \multicolumn{1}{c}{ Item } & CON & T1 & T2 & SE & p-value \\
\hline pH & 5.83 & 5.96 & 5.90 & 0.02 & 0.136 \\
TBARS $(\mathrm{mg} \mathrm{MA} / \mathrm{kg})$ & $0.20^{\mathrm{a}}$ & $0.19^{\mathrm{a}}$ & $0.17^{\mathrm{b}}$ & 0.01 & $<.0001$ \\
\hline
\end{tabular}

Each value is the mean value of 10 replicates ( 2 broilers/cage).

a,b Means in the same row with different superscripts differ $(p<0.05)$.

CON, basal diet; $\mathrm{T} 1$, basal diet $+0.1 \%$ exogenous emulsifier; $\mathrm{T} 2$, basal diet $+0.2 \%$ exogenous emulsifier; SE, standard error. 
hours [42]. In this experiment, all $\mathrm{pH}$ values were within the normal range. Therefore, the addition of exogenous emulsifier to broiler feed is considered to have no significant effect on $\mathrm{pH}$.

The rancidity of meat fat is an indicator of the degree of lipid oxidation and the quality of meat decreases as lipids are degraded by lipolytic enzymes and microbial metabolism $[43,44]$. In a study by Kim et al. [34], there was no significant difference in the TBARS value as a result of adding lecithin to pig feed. However, the study with soy lecithin in broiler feed showed that the TBARS value declined with the addition of lecithin [45]. Likewise, this experiment showed a positive effect by the addition of exogenous emulsifier, similar to the experiment by Nagargoje [45]. It is assessed that the TBARS value is fresh in the range of $0.2 \mathrm{mg}$ malondialdehyde (MA)/ $\mathrm{kg}$ or less, and that 4.0 $\mathrm{mg} \mathrm{MA} / \mathrm{kg}$ or more is rancid (Brewer et al., 1992). However, the results of this test are all within the normal range because the values are less than 0.2. The supplementation of exogenous emulsifier was considered to have no significant effect, although there was a significant difference in TBARS.

\section{CONCLUSION}

In this experiment, the addition of $0.1 \%$ exogenous emulsifier to broiler feed lowered the FCR and improved the growth performance. Also, the addition of $0.2 \%$ exogenous emulsifier improved meat quality by increasing the $\mathrm{WHC}$ and decreasing the shearing force of broiler breast meat. However, research on the optimal amount of exogenous emulsifier to add in broiler feed is insufficient. Therefore, future research must identify the optimal level of exogenous emulsifier supplementation.

\section{REFERENCES}

1. Griffin WC. Calculation of HLB values of non-ionic surfactants. J Soc Cosmet Chem. 1954;5:249-56.

2. Van der Heijden M, de Haan D. Optimizing moisture while maintaining feed quality. All About Feed. 2010. https://www.allaboutfeed.net/Processing/Cooling--Drying/2010/10/Optimising-moisture-while-maintaining-feed-quality-AAF011514W/. Accessed 29 Oct 2019.

3. Kang KC, Jeong NH. A study on the stability of emulsion by polyglycerol ester.J Korean Appl Sci Technol. 2013;30:152-9.

4. Tan HS, Zulkifli I, Farjam AS, Goh YM, Croes E, Partha SK, et al. Effect of exogenous emulsifier on growth performance, fat digestibility, apparent metabolisable energy in broiler chickens.J Biochem Microbiol Biotechnol. 2016;4:7-10.

5. Roy A, Haldar S, Mondal S, Ghosh TK. Effects of supplemental exogenous emulsifier on performance, nutrient metabolism, and serum lipid profile in broiler chickens. Vet Med Int. 2010;2010:262604.

6. Zhang B, Haitao L, Zhao D, Guo Y, Barri A. Effect of fat type and lysophosphatidylcholine addition to broiler diets on performance, apparent digestibility of fatty acids, and apparent metabolizable energy content. Anim Feed Sci Techol. 2011;163:177-84.

7. Dierick NA, Decuypere JA. Influence of lipase and/or emulsifier addition on the ileal and faecal nutrient digestibility in growing pigs fed diets containing $4 \%$ animal fat. J Sci Food Agric. 2004;84:1443-50.

8. Lazaro R, Latorre MA, Medel P, Gracia M, Mateos GG. Feeding regimen and enzyme supplementation to rye-based diets for broilers. Poult Sci. 2004;83:152-60.

9. Polin D. Increased absorption of tallow with lecithin. Poult Sci. 1980;59:1652.

10. Krogdahl A. Digestion and absorption of lipids in poultry. J Nutr. 1985;115:675-85.

11. Jones DB, Hancock JD, Harmon DL, Walker CE. Effects of exogenous emulsifiers and fat 
sources on nutrient digestibility, serum lipids, and growth performance in weanling pigs. J Anim Sci. 1992;70:3473-82.

12. Al-Marzooqi W, Leeson S. Evaluation of dietary supplements of lipase, detergent, and crude porcine pancreas on fat utilization by young broiler chicks. Poult Sci. 1999;78:1561-6.

13. Soares M, Lopez-Bote CJ. Effects of dietary lecithin and fat unsaturation on nutrient utilisation in weaned piglets. Anim Feed Sci Techol. 2002;95:169-77.

14. Gu X, Li D. 2003. Fat nutrition and metabolism in piglets: a review. Anim Feed Sci Technol. 2003;109:151-70.

15. Bontempo V, Comi M, Jiang XR, Rebucci R, Caprarulo V, Giromini C, et al. Evaluation of a synthetic emulsifier product supplementation on broiler chicks. Anim Feed Sci Techol. 2018;240:157-64.

16. Xing JJ, van Heugten E, Li DF, Touchette KJ, Coalson JA, Odgaard RL, et al. Effects of emulsification, fat encapsulation, and pelleting on weanling pig performance and nutrient digestibility. J Anim Sci. 2004;82:2601-9.

17. National Research Council [NRC]. Nutrient requirements of poultry. 9th ed. Washington, DC: National Academy Press; 1994.

18. Laakkonen E, Wellington GH, Sherbon JN. Low-temperature, long-time heating of bovine muscle 1. Changes in tenderness, water-binding capacity, $\mathrm{pH}$ and amount of water-soluble components.J Food Sci. 1970;35:175-7.

19. Witte VC, Krause GF, Bailey ME. A new extraction method for determining 2-thiobarbituric acid values of pork and beef during storage.J Food Sci. 1970;35:582-5.

20. Gheisar MM, Hosseindoust A, Kim HB, Kim IH. Effects of lysolecithin and sodium stearoyl-2-lactylate on growth performance and nutrient digestibility in broilers. Korean J Poult Sci. 2015;42:133-7.

21. Dabbou S, Schiavone A, Gai F, Martinez S, Madrid J, Hernandez F, et al. Effect of dietary globin, a natural emulsifier, on the growth performance and digestive efficiency of broiler chickens. Ital J Anim Sci. 2019;18:530-7.

22. Zhao PY, Kim IH. Effect of diets with different energy and lysophospholipids levels on performance, nutrient metabolism, and body composition in broilers. Poult Sci. 2017;96:1341-7.

23. Kaczmarek SA, Bochenek M, Samuelsson AC, Rutkowski A. Effects of glyceryl polyethylene glycol ricinoleate on nutrient utilisation and performance of broiler chickens. Arch Anim Nutr. 2015;69:285-96.

24. Zaefarian F, Romero LF, Ravindran V. Influence of high dose of phytase and an emulsifier on performance, apparent metabolisable energy and nitrogen retention in broilers fed on diets containing soy oil or tallow. Br Poult Sci. 2015;56:590-7.

25. Zhao PY, Li HL, Hossain MM, Kim IH. Effect of emulsifier (lysophospholipids) on growth performance, nutrient digestibility and blood profile in weanling pigs. Anim Feed Sci Techol. 2015;207:190-5.

26. Jansen M, Nuyens F, Buyse J, Leleu S, Van Campenhout L. Interaction between fat type and lysolecithin supplementation in broiler feeds. Poult Sci. 2015;94:2506-15.

27. Choi YS, Choi JH, Han DJ, Kim HY, Lee MA, Kim HW, et al. Characteristics of low-fat meat emulsion systems with pork fat replaced by vegetable oils and rice bran fiber. Meat Sci. 2009;82:266-71.

28. Wu FY, Smith SB. Ionic strength and myofibrillar protein solubilization. J Anim Sci. 1987;65:597-608.

29. Li TS, Liu WC, Zhao PY, Kim IH. Evaluation of essential oil or/and emulsifier in low energy density diets on growth performance, nutrient digestibility, blood cholesterol and meat quality 
in finishing pigs. Ital J Anim Sci. 2017;16:624-30.

30. Upadhaya SD, Lee JS, Jung KJ, Kim IH. Influence of emulsifier blends having different hydrophilic-lipophilic balance value on growth performance, nutrient digestibility, serum lipid profiles, and meat quality of broilers. Poult Sci. 2018;97:255-61.

31. Froning GW, Babji AS, Mather FB. The effect of preslaughter temperature, stress, struggle and anesthetization on color and textural characteristics of turkey muscle. Poult Sci. 1978;57:630-3.

32. Barbut S. Colour measurements for evaluating the pale soft exudative (PSE) occurrence in turkey meat. Food Res Int. 1993;26:39-43.

33. Northcutt JK, Foegeding EA, Edens FW. Water-holding properties of thermally preconditioned chicken breast and leg meat. Poult Sci. 1994;73:308-16.

34. Kim WT, Shinde P, Chae BJ. Effect of lecithin with or without chitooligosaccharide on the growth performance, nutrient digestibility, blood metabolites and pork quality of finishing pigs. Can J Anim Sci. 2008;88:283-92.

35. Akit H, Collins CL, Fahri FT, Hung AT, D'Souza DN, Leury BJ, et al. Dietary lecithin improves dressing percentage and decreases chewiness in the longissimus muscle in finisher gilts. Meat Sci. 2014;96:1147-51.

36. Cho SH, Kim JH, Seong PN, Cho YM, Chung WT, Park BY, et al. Physico-chemical meat quality properties and nutritional composition of Hanwoo steer beef with 1++ quality grade. Korean J Food Sci Anim Resour. 2008;28:422-30.

37. Khan AW, Van den Berg L. 1964. Some protein changes during post-mortem tenderization in poultry meat. J Food Sci. 1964;29:597-601.

38. Bouton PE, Harris PV. 1972. The effects of cooking temperature and time on some mechanical properties of meat.J Food Sci. 1972;37:140-4.

39. D'Souza DN, Mullan BP, Pethick DW, Pluske JR, Dunshea FR. Nutritional strategies affect carcass and pork quality but have no effect on intramuscular fat content of pork. Anim Prod Sci. 2012;52:276-82.

40. Liu SD, Song MH, Yun W, Lee JH, Lee CH, Kwak WG, et al. Effects of oral administration of various essential oils on blood metabolites, intestine development, microbial enumeration and meat quality in broilers. Indian J Anim Res. 2019;53:762-7.

41. Upadhaya SD, Park JW, Park JH, Kim IH. 2017. Efficacy of 1,3-diacylglycerol as a fat emulsifier in low-density diet for broilers. Poult Sci. 2017;96:1672-8.

42. Penny IF. The effect of temperature on the drip, denaturation and extracellular space of pork longissimus dorsi muscle. J Sci Food Agric. 1977;28:329-38.

43. Brewer MS, Ikins WIG, Harbers CAZ. TBA values, sensory characteristics, and volatiles in ground pork during long-term frozen storage: effects of packaging.J Food Sci. 1992;57:558-63.

44. Raharjo S, Sofos JN. Methodology for measuring malonaldehyde as a product of lipid peroxidation in muscle tissues: a review. Meat Sci. 1993;35:145-69.

45. Nagargoje SB, Dhumal MV, Nikam MG, Khose KK. Effect of crude soy lecithin with or without lipase on performance and carcass traits, meat keeping quality and economics of broiler chicken. Int J Livest Res. 2016;6:46-54. 